\title{
PARA QUE SERVE A FILOSOFIA? O ENSINO DE FILOSOFIA COMO MEIO ADEQUADO PARA A REALIZAÇÃO DOS FINS DA EDUCAÇÃO BRASILEIRA ${ }^{1}$
}

\author{
WHAT PHILOSOPHY IS USED FOR? THE TEACHING OF \\ PHILOSOPHY AS APPROPRIATE MEANS FOR THE \\ ACCOMPLISHMENT OF BRAZILIAN EDUCATION PURPOSES
}

Fábio Baltazar do Nascimento Júnior

Recebido: 08/2019

Aprovado: 11/2019

\begin{abstract}
Resumo: Com base em uma interpretação de três finalidades básicas da educação brasileira listadas na Lei de Diretrizes e Bases da Educação Nacional (LDB), a saber, o desenvolvimento do educando, o exercício da cidadania e a qualificação para o mercado de trabalho, procuramos desenvolver sugestões de como o ensino da Filosofia pode ser um meio adequado para a realização de cada um desses objetivos gerais da Educação.
\end{abstract}

Palavras-chave: Educação; Filosofia; Utilidade

\begin{abstract}
Based on an interpretation of three basic purposes for Brazilian education, which are listed on National Education Guidelines and Framework Law (LDB), namely, the development of the student, the exercise of citizenship and the qualification for the labor market, we seek to develop suggestions of how the teaching of philosophy can be an appropriate means for the accomplishment of each of these general objectives of education.
\end{abstract}

Keywords: Education; Philosophy; Utility.

Em 10 de outubro de 2016, João Vergílio Gallerani Cuter publicou, no site da Associação Nacional de Pós-Graduação em Filosofia (Anpof), um texto que começa com um lamento. O professor dizia-se "emocionalmente inclinado" a defender a obrigatoriedade do ensino de Filosofia no Ensino Médio, porque a presença da disciplina no currículo escolar implicaria reservar emprego para os colegas, mas que, infelizmente, a razão fria o forçaria a recusar a obrigatoriedade. Amicus philosophorum sed magis amica veritas.

O preâmbulo talvez cumpra certa função retórica de apresentar um homem triste, que

\footnotetext{
${ }^{1}$ Possui graduação (2008) e mestrado (2012) em Filosofia pela Universidade Federal de Uberlândia. Atualmente é professor efetivo da Universidade Federal de Uberlândia e doutorando em Filosofia pela Università del Salento (Lecce-Itália). E-mail: fabiobnj@hotmail.com.
} 
porém enfrenta heroicamente seus sentimentos em nome da mais alta racionalidade, como se ele fosse capaz de equilibrar os sentimentos mais ternos e a apoditicidade de um Gödel. Um homem de ethos a domar suas paixões para nos iluminar com o mais puro logos. Vejamos como se desenvolve essa promessa de refrescar-nos com o gelo parmenidiano.

Cuter informa-nos que o argumento pro obrigatoriedade da Filosofia a ser avaliado é o de que a disciplina seria importante para formar "cidadãos críticos", que ele interpreta como "cidadãos capazes de um tipo mais qualificado de avaliação da sociedade em que estão inseridos, das informações que recebem pelos meios de comunicação, dos argumentos e alegações apresentados por seus representantes políticos, e assim por diante." Contra essa tese de que a obrigatoriedade justificar-se-ia por esse fim, o autor diz-nos que o ensino do Direito, por exemplo, talvez cumprisse igualmente a função de formar os tais cidadãos críticos e que poderia ficar a cargo da escola escolher se preferiria ensinar Direito ou Filosofia. Cuter avança dizendo, então, que alguém poderia objetar que as disciplinas não se excluem mutuamente e que, embora a ideia de Filosofia como fundamentadora dos demais saberes causasse-lhe "calafrios", alguns argumentariam que a Filosofia e o Direito se complementariam na medida em que este fornecesse a prática e aquela a teoria fundante. $\mathrm{O}$ autor limita-se, em seguida, a espalhar outras disciplinas na mesa e questionar por que, então, a Sociologia, a Música ou a Educação Ambiental deveriam ser excluídas dessa "escola ideal". Em suma, como pergunta o próprio Cuter, “por que tornar Descartes obrigatório, mas Beethoven opcional?"

Depois de lutar sem sucesso contra essa suposta arbitrariedade da inclusão da Filosofia no currículo enquanto isto custasse a exclusão de Beethoven, Cuter volta ao início, como se só restasse, afinal, o argumento corporativista: dar emprego aos colegas.

Escolher a Filosofia como obrigatória seria, então, arbitrário. Mas não fica claro na argumentação de Cuter por que razão, no fim das contas, alguma disciplina deveria ser obrigatória. A inquestionada Língua Portuguesa não poderia, afinal, ser substituída pelo Latim e pela leitura dos clássicos? A Matemática como é ensinada não poderia ser substituída por um curso sobre os Elementos? Se não haveria razões para Descartes estivesse no currículo sem que também puséssemos Beethoven, por que Newton deveria continuar na escola em vez de Wagner? Por que não avançar para a arbitrariedade do currículo inteiro? Talvez Cuter não quisesse ir tão longe e preferisse limitar seu questionamento ao acréscimo de obrigatórias sem se perguntar pelo que fundamenta a escolha das obrigatórias dadas. Ele talvez desejasse partir do dado bruto e evitar os voos de Ícaro ou, como ele mesmo diz no texto, argumentar de um ponto de vista "essencialmente prático". Lembremos, porém, que àquela altura a Filosofia era 
obrigatória desde 2008, e que a discussão era sobre retirá-la, não acrescentá-la. De um ponto de vista "essencialmente prático", poderia até fazer algum sentido diluir a importância da Filosofia abrindo um leque de candidatas como a Música e o Direito se o debate fosse o de acrescentá-la. Para retirá-la, a exibição da arbitrariedade da escolha do currículo exige que nos perguntemos por que teria de ser a Filosofia - e não a Língua estrangeira - a escolhida para deixar o Ensino Médio.

O texto de Cuter tem uma virtude evidente: ele expõe até certo ponto a fragilidade do argumento da formação do "cidadão crítico" entendido como juiz de assuntos públicos ou, mais exatamente, da redução da importância educativa da Filosofia ao fornecimento de instrumentos para análise de discurso de político ou para que o cidadão "faça valer seus direitos", sobretudo o cidadão entendido como indivíduo partícipe de uma democracia liberal. Ademais, realmente a ideia de relacionar o Direito e a Filosofia a partir do par fundado-fundante parece esbarrar no fato de que a Filosofia, embora mergulhe em busca do fundamento, dificilmente o estabelece. O estabelecimento do fundamento costuma resultar de certo abandono da Filosofia, de certa desistência, como se o filósofo deixasse sua pá de lado, como diria Nietzsche.

Além disso, o texto põe a questão toda em termos corretos: estamos discutindo na verdade o que um jovem deve aprender no ensino médio. Em outras palavras, não se trata de "defender" a Filosofia no currículo dos jovens como se tudo dependesse de uma retórica corporativista, a partir do argumento maroto de que a escolha do currículo inteiro não é mais que o resultado de uma disputa política. Não se trata de dizer que possamos excluir a dimensão política da escolha do currículo escolar, inclusive porque há um sentido inescapável da consideração dessa dimensão: a inclusão ou exclusão de uma disciplina depende do assentimento do ente detentor do poder. Em síntese, precisamos da anuência do rei. Ainda assim, não há outra saída: se formos capazes de convencer o rei, é melhor que façamos isto com mais apelo a razões que ao pathos. No fim das contas, ainda que não tenhamos sucesso na persuasão, a história talvez possa julgar que tínhamos razão.

Precisaremos, então, descobrir se há razões para ensinar Filosofia a um jovem adolescente. Mais ainda: parece haver razões óbvias - como há boas razões para ensinar Música - e elas não bastam. É preciso descobrir se o ensino da Filosofia combina com os objetivos mais fundamentais que traçarmos para a Educação brasileira. Não se trata simplesmente de defendêla como atividade intelectual, pois sabemos da dificuldade de destroná-la: "se não é preciso filosofar, então é preciso filosofar", algo parecido teria dito Aristóteles no Protréptico ${ }^{2}$.

\footnotetext{
${ }^{2}$ Fragmentos 5-6. Cf. Aristóteles, 2006.
} 
Estamos atrás de algo mais que a simples dignidade da disciplina: queremos saber se o seu ensino é um bom meio para cumprir certos fins educacionais.

Já deve estar claro que não pensamos que um currículo escolar seja em si mesmo arbitrário. Ele atende a anseios culturais que o antecedem. Ele funciona como meio para finalidades educacionais que, embora elas próprias possam ter algo de arbitrário, atuam, como qualquer finalidade instituída, na restrição da escolha dos meios. Em sentido muito geral, podemos dizer que vários meios atingem o mesmo fim, mas algumas atitudes nos distanciam dele, outras atrasam e outras dificultam sua consecução. O ensino da Filosofia alinha-se com as finalidades educacionais que estão no espírito do nosso tempo e lugar?

A pergunta por fins educacionais é, na verdade, uma pergunta pelo humano a ser formado. Não se trata do humano ideal, mas do humano com quem queremos conviver. A questão supõe, um pouco ao arrepio do eidético, certa plasticidade do que se entende por humano. A questão dá a entender, ainda, que há humanidades que não nos interessam mais ou que preferimos não formar. Não queremos formar nazistas, por exemplo, porque não somos nazistas e rejeitamos o homem nazista, embora um bom aluno da juventude hitlerista certamente se levantasse indignado contra a nossa confissão de que não queremos gente como eles. Isso se concretiza, por exemplo, no fato de não querermos jovens que apreciem só a arte ariana e rejeitem a arte degradada, de não querermos jovens que tenham Mein Kampf como breviário ou de não querermos jovens que cuspam em judeus.

A propósito, façamos um parêntese para instituir uma lei: se a educação for propagandista como a educação nazista, a Filosofia deve ser expulsa do currículo. É quase paradoxal que ministros de Estado e pessoas que se apresentem como intelectuais vejam no ensino da Filosofia nada mais que doutrinação ideológica. É a Filosofia a arma mais letal contra a ideologia. Ver-se no meio do embate entre Platão e Aristóteles, Tomás de Aquino e Descartes, Leibniz e Kant, Hegel e Marx - que sentimento pode ter um jovem estudante diante dessa gigantomachia senão o de perplexidade? Toda vez que alguém se aferra a alguma ideologia barata é mais provável que seja por falta de filosofia. A única disciplina preocupada com a avaliação das certezas não pode ser a culpada pela paixão por dogmas infundados.

Voltemos à reflexão sobre os fins educacionais. Se quisermos defender a presença da Filosofia no currículo, precisamos tentar entender o que pretende um currículo escolar. Talvez possamos chegar a algo mais concreto se listarmos alguns fins formativos com os quais todos ou a maioria - estejam de acordo.

Em sentido mais prosaico, talvez seja mais fácil começar pelos fins instituídos em lei. 
$\mathrm{O}$ artigo $2^{\circ}$ da Lei de Diretrizes e Bases da Educação Nacional (LDB) enuncia de modo rapsódico três fins muito gerais: a) o pleno desenvolvimento do educando; b) o preparo do educando para o exercício da cidadania; c) a qualificação do educando para o trabalho. Uma vez que esses fins são excessivamente abstratos, é evidente que será preciso interpretá-los em certo sentido, dar a eles um significado mais concreto. Esperamos, porém, que o modo como interpretamos esses fins seja legítimo. Acreditamos que, se bem interpretados esses fins, o estudo de Filosofia é um excelente meio para a realização de cada um deles.

$\mathrm{Na}$ ideia de "pleno desenvolvimento do educando" parece estar contido o desenvolvimento intelectual e moral. Obviamente, poderíamos acrescentar o desenvolvimento de um corpo saudável, de habilidades motoras, de técnicas para o trabalho, de sociabilidade etc. Em última análise, há também um sentido em que todas as habilidades se conectam, já que o aprendizado das técnicas para o trabalho exige certo desenvolvimento intelectual, a sociabilidade exige certas reflexões morais, habilidades motoras requerem um corpo minimamente saudável e assim poderíamos continuar a estabelecer intersecções. Ponhamos, contudo, a questão do seguinte modo: a) se pudermos, para fins de argumentação, destacar com um bisturi lógico o desenvolvimento intelectual e moral, na medida em que essa abstração parece mais direta e intuitivamente conectada à Filosofia e b) se for verdade que a escola está preocupada com o desenvolvimento do educando também no sentido intelectual e moral, então c) o estudo de Filosofia poderá ajudar bastante nesse desenvolvimento do educando, já que a leitura de textos de filosofia - e o consequente contato com princípios, argumentos e modos de pensar diversos - pode melhorar algumas capacidades intelectuais e elevar a qualidade da reflexão moral.

Em sentido intelectual, ainda que não pretendamos exaustividade, diríamos que o estudo de Filosofia certamente melhora as capacidades de: a) construir opiniões mais consequentes e fundamentadas; b) exigir padrões mais elevados de apoditicidade em teorias, o que pode levar a duvidar de pseudociências, de teorias conspiratórias etc; c) pensar alternativas diante do que está dado como aparentemente certo ou incontornável; d) preferir a investigação à aceitação acrítica de testemunhos ou opiniões alheias, o que é fundamental em tempos de fake news, por exemplo; e) na medida do possível, integrar a própria visão de mundo de modo mais coerente, isto é, enxergar o saber como uma unidade, resistindo à fragmentação e à instrumentalização do conhecimento; f) quase paradoxalmente, se considerarmos a capacidade anterior, visualizar os saberes em construção permanente a partir de uma história de longue durée, marcada por continuidades, rupturas, pela constituição de novas racionalidades, de novas epistemologias, 
novas ontologias, novos pressupostos metafísicos e, claro, pela permanente revisitação das "velhas". Digo "quase paradoxalmente", porque é fácil de solucionar a aparente contradição: quem toma para si a tarefa de filosofar procurará integrar coerentemente a própria visão de mundo diante da miríade de possibilidades dadas na história da Filosofia, reconhecendo os conflitos entre os pensamentos, de modo que possa escolher caminhos compatíveis entre si ou, se possível, resolver as inconsistências em sínteses mais amplas. Todas essas possibilidades são figuras de um conceito de filosofia como crítica - isto é, krísis, iudicium, capacidade de julgar - unida à investigação - ou seja, sképsis ou exercício cético em sentido fundamental. Uma vez que essas categorias da crítica e da investigação são gerais, penso que sejam aplicáveis a quase todos os filósofos, do exercício cético - a admiração como impulso para a investigação - de um Aristóteles em busca das causas à crítica kantiana, isto é, a razão julgada num tribunal atento à universalidade e à necessidade tomadas como lei. O estudo desses movimentos do pensamento por meio dos textos dos filósofos é uma chave mestra de desenvolvimento intelectual do educando, dificilmente superável por qualquer outra disciplina.

Como já dissemos, em sentido moral, o estudo da Filosofia ajuda na elevação da qualidade da reflexão acerca de uma moralidade laica. Sobre isto, é bom descartar, de início, um mal entendido possível. Nem a Filosofia, nem a Igreja, nem o chicote, nem os juízes, nenhum mandamento ou autoridade são capazes de forçar os agentes morais a agir preocupados com a possibilidade de justificar os próprios atos considerando também os outros. O estudo da Filosofia pode, por outro lado, dar elementos laicos - isto é, públicos, independentes de escolha pessoal de fé e com pretensão de validade para todos - para o debate acerca do aceitável e do justificável.

Nada disso é livre de problemas ou de fatos que possam parecer desanimadores para aqueles que esperam que a razão seca dê conta de problemas existenciais. Talvez a moral erigida por uma reflexão filosófica, diferentemente da moral religiosa, reconheça mais abertamente a possibilidade do conflito, do dilema, da justificação para fazer ou não determinada coisa em algumas situações, embora também as religiões às vezes divirjam entre si - ou mesmo internamente - acerca de uma regra moral. Parece verdadeiro, porém, que a moral pensada em sentido público, laico, tenha mais espaço para o que Sartre chamava de angústia: postos diante de uma situação de escolher como agir, a liberdade laica muitas vezes nos assusta pela desorientação fundamental que ela implica.

Ademais, a abertura para a reflexão laica sobre a moral parece lançar as questões sexuais, tão caras às maiores religiões, para um terreno mais íntimo do que aquele que essas 
questões ocupariam, por exemplo, numa moralidade cristã. Enquanto as orientações sexuais e as práticas sexuais são um problema público numa moral do pecado, numa moral laica essas questões parecem destinadas a serem relegadas ao âmbito privado. Evidentemente, isso não quer dizer que as questões sexuais deixem de ser discutidas publicamente, mas que a discussão acerca delas tenderá a selecionar, entre as inúmeras práticas sexuais, o que teria relevância pública. A tendência será de discuti-las do ponto de vista das suas implicações para a saúde, de modo que questões de prudência são postas, das responsabilidades que podem surgir da atividade sexual, isto é, da possibilidade da gravidez precoce ou indesejada, da idade de consenso e do consenso de fato, o que leva ao problema de discutir a essência do estupro e a questão moral da pedofilia e outras coisas desse tipo. Mas sobre a natureza da prática, isto é, se o sexo acontece entre pessoas do mesmo sexo ou de sexos opostos, se é feito entre duas pessoas ou entre várias, se é praticado como um ato meramente lúdico ou para fins de reprodução, todos esses elementos que não parecem em si mesmos ter relevância pública séria, ainda que alguns possam acidentalmente vir a ter importância pública em determinadas situações, todos esses serão relegados ao âmbito do gosto, sobre o que a moral não teria muito a dizer.

O que se ganha, então, com a Filosofia, se considerarmos a ideia de desenvolvimento moral do educando? Nada além do mais fundamental: destronada a religião de seu caráter de senhora da moral pública, só a Filosofia pode ser posta no trono vago. Isso não quer dizer que a Filosofia venha a se tornar uma consultora existencial, uma preceptística elencada em um código de ética universal ou que os filósofos possam formar Concílios para determinar os rumos da humanidade, mas que a disciplina dá ao cidadão os elementos para que ele possa refletir sobre o que ele e os outros devem fazer a partir de razões públicas. Concretamente, a consciência de certa principiologia ética, mesmo com as dificuldades de conciliar uma ética das virtudes, uma ética consequencialista e uma ética deontológica, embora não necessariamente tenha força de levar à agência moral, coloca o cidadão diante das questões que orientarão as discussões que podemos travar numa democracia que respeite a laicidade do Estado.

Diferentemente do que se poderia objetar, o Direito ou, quem sabe, a Antropologia nada podem fazer quanto a esse papel filosófico fundamental. O Direito positivo não tem nada a dizer ao povo reunido em assembleia, a não ser o fato banal de que há regras muito fundamentais a seguir. Mas, na medida em que se trata do povo a discutir a lei a ser instituída, o Direito é uma ocupação secundária à Filosofia enquanto amparo para o debate público mais originário. A Antropologia, por seu turno, despe-se do julgamento moral em busca de sua dignidade epistemológica, então, nada tem a dizer acerca do que deveríamos fazer, ainda que 
diga o que os homens fazem de fato. $\mathrm{Na}$ verdade, as conquistas epistemológicas mais importantes da Antropologia - a rejeição do etnocentrismo e o relativismo cultural - são muitas vezes confundidas com a necessidade de aferrar-se a um relativismo moral, o que é um non sequitur.

Em suma, do ponto de vista de melhorar capacidades intelectuais mais fundamentais, a Filosofia é a disciplina mais adequada para cumprir esse melhoramento. Do ponto de vista da reflexão moral orientada por razões públicas e laicas, também a Filosofia põe-se como candidata eminente. Se o desenvolvimento intelectual e moral do educando está entre os fins fundamentais da Educação Brasileira, então a Filosofia - e nenhuma outra disciplina é melhor para esses fins - deve ter uma presença considerável no currículo escolar.

O segundo fim elencado pela LDB é o "preparo para o exercício da cidadania". Já expusemos que consideramos um erro reduzir a Filosofia para esse fim, que seria o de formar o cidadão crítico, capaz de fazer valer seus direitos e de avaliar discursos de políticos, dos meios de comunicação etc. E, de fato, para esse fim, o Direito parece concorrer com a Filosofia, sobretudo se partirmos sempre do pressuposto de que o cidadão é o indivíduo senhor de direitos - de direitos políticos e de direitos fundamentais como a vida, as liberdades, a propriedade etc - que dá corpo ao soberano de uma democracia de tipo liberal. Ainda não dissemos, porém, que há outros sentidos de "cidadão crítico" na medida em que o conceito de crítica não se resume à capacidade de julgar a verdade ou a cogência de um argumento, mas também de ser juiz da própria realidade dada. Uma vez que a Filosofia tem uma potência de desnaturalizar o próprio Direito, o conceito de cidadão crítico pode significar o cidadão cosmopolita, livre das cercas constitucionais, capaz de propor ao país e ao mundo caminhos e modos de vida diversos dos dados por amarras legais ou institucionais. Obviamente, não se trata de transgredir a lei, mas de abrir, para a própria comunidade ou para além dela, a possibilidade de transformá-la, na medida em que as realidades legal, sócio-econômica, cultural e, quiçá, aquelas tratadas falsamente como naturais estariam, como tais, sob o escrutínio da crítica. Nesse sentido, o estudo do Direito poderia ajudar muito menos que o estudo da Filosofia. Só a radicalidade filosófica pode, com o seu olhar atento à raiz do instituído e às falsas necessidades, propor o que não está realizado.

Talvez o leitor se incomode com o caráter de exclusividade que temos dado à Filosofia. O que quer dizer que "só a Filosofia" pode isso ou aquilo? Não estão as ciências e as tecnologias mudando a realidade o tempo todo? Não estão os juristas propondo alternativas legais? Os economistas, os artistas, as pessoas sem formação escolar etc? Sim, elas estão. Mas sempre fazem transformações quando se posicionam como críticos do dado, isto é, quando são capazes 
de julgar o que está estabelecido, resgatando a potência filosófica que têm dentro de si. Isso quer dizer que o ensino escolar da Filosofia não é requisito indispensável para assumir uma postura filosófica. Na verdade, nenhum ensino escolar é necessário para que se atinja qualquer saber. Porém, na medida em que há um currículo escolar que sirva de meio para fins determinados, o ensino de Filosofia é o caminho mais curto para que os educandos se tornem mais críticos no sentido amplo do termo, que compreenda desde a capacidade de julgar teorias à capacidade de pôr em questão a própria realidade estabelecida, procurando continuamente o limite entre a necessidade e a liberdade.

A terceira e última finalidade listada pela LDB é "a qualificação do educando para o trabalho". O sentido comum de "qualificar-se para o trabalho" implica o aprendizado de um ofício. Trata-se de aprender a fazer sapato, de aprender a construir um aplicativo ou de aprender a operar uma planilha de custos. Evidentemente, também nesse sentido mais corriqueiro a escola é preparatória. Mas é claro que os conhecimentos aprendidos na escola visam preparar o educando para que ele compreenda o que faz. 'Compreender' o próprio ofício é percebê-lo no interior das relações humanas e dos saberes necessários para o bom desempenho daquele ofício. Há camadas de compreensão em qualquer ofício desempenhado: talvez seja possível fazer sapato apenas seguindo certas instruções, certo receituário, mas também é possível fazer melhores sapatos com certos conhecimentos de anatomia, também é possível fazer sapatos compreendendo as questões éticas relacionadas à produção do couro etc. É comum que se ouça a repreenda de que a escola ensina coisas inúteis, que Bhaskara ou que os detalhes do golpe de 64 não servem para nada porque nunca são usados de fato na vida do trabalho. Mas esse tipo de crítica à escola tem por base um entendimento empobrecido do significado da finalidade de qualificação para o trabalho que o saber escolar objetiva cumprir. A qualificação para o trabalho precisa ser pensada como capacitação para desempenhar um ofício no interior de uma vida pública complexa, que envolve a economia, a política, a ciência, as artes, a cultura, a história etc. Nesse sentido, a Filosofia desponta como fundamental para ajudar no cumprimento dessa qualificação para o trabalho entendida compreensivamente, já que a Filosofia é um saber integrado, interdisciplinar, crítico, investigativo e radical. É pela Filosofia e por uma reflexão sobre os princípios das ciências, das artes e da inteligência que alguém é capaz de ampliar o quadro compreensivo, de se enxergar com mais clareza no mundo do trabalho.

Essa situação liga-nos, finalmente, a uma finalidade geral da Educação. Está na ordem do dia a tese de que a escola tem de ensinar apenas a ler e a calcular, e que todo o resto seria papel da família, da Igreja, da iniciativa individual etc. Dizem alguns: a escola instrui e a família 
educa. A escolha dos termos não é feliz: a) in struo é construir dentro, isto é, empilhar coisas na cabeça dos outros, de modo que o termo serviria tanto para uma escola cheia de literatura quanto para uma escola em que só se ensina a codificar os sons pelas sílabas; b) ex duco é conduzir para fora, ou seja, o sentido primordial de educar é fazer que o educado saia da idiotia, que se reconheça não apenas como membro de uma família, mas também como membro de uma comunidade mais ampla. Em todo caso, com a tese de que a escola só ensina a ler e a calcular, decreta-se a expulsão da literatura brasileira e mundial, da História, das ciências naturais, das artes etc. O problema está na tese: a escola ensina, evidentemente, a ler e a calcular, mas ela também precisa ensinar o que ler e o que calcular. A escola precisa de literatos e de cientistas, não só de cartilhas. A escola direciona o educando para os clássicos da literatura universal e mostra aos adolescentes que é possível calcular o próximo eclipse. A escola mostra o valor de Machado de Assis, de Lima Barreto, de Guimarães Rosa e de Chico Buarque, mas também evidencia as aplicações do triângulo de Pascal em Genética. Obviamente, também, a escola mostra que é possível pensar sobre o significado e a racionalidade do movimento ao ler um poema de Parmênides e um argumento de Zenão de Eleia, bem como instrui sobre as condições filosóficas a partir das quais o movimento pode ser calculado. Em suma, não é possível reduzir a escola à cartilha. Há um processo formativo gradativo e cumulativo que, necessariamente, será obrigado a se perguntar pelo que ler e pelo que calcular. Feita a pergunta, a Filosofia certamente está entre as respostas: não é razoável uma escola que sonegue aos educandos a leitura da República, da Metafísica, da Suma Teológica, do Discurso do Método, da Crítica da Razão Pura, da Fenomenologia do Espírito e de inúmeros clássicos sem os quais nenhuma formação escolar é completa. Vale dizer que não bastará, porém, a leitura espontaneísta desses clássicos. É imprescindível a presença de um professor de Filosofia treinado nessas leituras para que ele possa orientar os educandos. Este argumento está longe de ser corporativista, ele está enraizado no conhecimento da própria formação do professor de Filosofia, que é treinado para ler tais textos, tanto quanto um matemático é treinado para resolver problemas e fazer demonstrações. Sem a orientação de um professor de Filosofia, esses textos serão, via de regra, incompreensíveis, ainda que lidos várias vezes.

Com base nessa particularidade da formação do professor de Filosofia, é importante avançar aqui uma tese plausível que, nos tempos atuais, talvez seja mais persuasiva que qualquer outro argumento que apele à natureza do saber: o estudo sério da Filosofia provavelmente melhorará as notas dos nossos educandos em exames nacionais como o Exame Nacional do Ensino Médio (Enem) e internacionais como o Programme for International 
Student Assessment (Pisa). Uma das competências fundamentais medidas pelo Pisa é a Leitura, que seria sem dúvida enriquecida pelo estudo de textos filosóficos. É claro que todas aquelas capacidades intelectuais já elencadas quando falávamos do desenvolvimento pleno do educando certamente contribuirão, também, para melhores resultados em exames.

Os professores de Filosofia não deverão negar que o ensino de Filosofia nas escolas secundárias ainda tenha desafios pedagógicos importantes. Para avançar nesses desafios, precisamos romper, contudo, a barreira da resistência à própria presença da disciplina no currículo. É preciso deixar que os professores de Filosofia experimentem, que concebam novos materiais, novas formas de abordar a disciplina, o que é, em síntese, o papel comezinho de todas as licenciaturas, da Matemática à História. Os burocratas da Educação brasileira precisam deixar que os filósofos trabalhem, precisam olhar para a disciplina com o respeito que é devido à história do pensamento e dos conceitos que orientam até mesmo as instituições que garantem a eles o próprio poder. Uma vez estabelecida a centralidade da Filosofia numa educação genuinamente brasileira, trabalharemos juntos para formar professores capazes de alterar profundamente a maneira como os nossos educandos são formados, com atenção aos fins educacionais aceitos por todos nós.

Como já dissemos, a exclusão a Filosofia é, no fim das contas, um ato político. Procurei mostrar apenas que a opção não é das mais coerentes com alguns fins muito gerais estabelecidos para a Educação brasileira.

\section{Referências}

ARISTÓTELES. Protréptico. Edição bilíngue. Tradução para o espanhol de Carlos Megino Rodriguez. Madrid: Abada Editores, 2006.

BRASIL. Ministério da Educação. LDB - Lei no 9394/96, de 20 de dezembro de 1996. Estabelece as diretrizes e bases da Educação Nacional. Brasília : MEC, 1996.

CUTER, J. Por que não defendo a obrigatoriedade da Filosofia no Ensino Médio? . Disponível em: $\quad<$ http://anpof.org/portal/index.php/en/comunidade/coluna-anpof/852-por-que-naodefendo-a-obrigatoriedade-da-filosofia-no-ensino-medio>. Acesso em 12 de Novembro de 2019. 